\title{
APLICAÇÃO DE REDES NEURAIS ARTIFICIAIS NA INDÚSTRIA DE FIOS DE ALGODÃO - DETERMINAÇÃO DO ÍNDICE DE FIBRAS IMATURAS
}

\section{APPLICATION OF ARTIFICIAL NEURAL NETS IN THE COTTON YARN INDUSTRY - DETERMATION OF INDEX OF IMMATURE FIBERS}

\author{
Gilberto Clóvis Antonelli ${ }^{1}$; Ivo Neitzel ${ }^{2}$ \\ ${ }^{1}$ Universidade Estadual de Maringá (UEM) - Maringá - Brasil \\ gcantonelli@uem.br \\ ${ }^{2}$ Faculdade de Telêmaco Borba- Telêmaco Borba - Brasil \\ ivo.neitzel@fatebtb.edu.br
}

\begin{abstract}
Resumo
Em uma indústria de fios de algodão, a quantidade de fibras imaturas é uma característica importante da matéria-prima, porque afeta diretamente a qualidade do processo de tingimento do fio produzido. Um desequilíbrio nutricional na planta de algodão pode ocasionar abertura dos capulhos (maçã do algodão aberta) tardiamente, ocasionando fibras imaturas, isto ocorre quando existe um excesso de nitrogênio ou uma abertura precoce, ou quando a adubação fosfatada é desproporcional. As fibras imaturas também formam neps, que são responsáveis por irregularidades no fio e também tendem a deixar pontos destacados após o tingimento, especialmente quando compostos por fibras imaturas. Com o objetivo de antever os problemas no tingimento de fios formados com um alto teor de fibras imaturas, desenvolveu-se um método de classificação das fibras de algodão utilizando as características (maturidade, alongamento $e$ micronaire) determinadas por equipamento HVI. Esse método consiste na elaboração de gráficos de correlação entre as variáveis, utilizando redes neurais artificiais para a construção dos mesmos. Analisando várias amostras de algodão e classificando-as com relação à apresentação de fibras imaturas após o tingimento, foi possível construir duas cartas de correlação com as quais se determina com precisão, o nível de fibras imaturas na amostra. Assim, o setor de PCP (Planejamento e Controle da Produção) pode antever problemas que ocorrerão após a fabricação $e$ o tingimento de um fio, utilizando amostras de matéria-prima, sem a necessidade de realizar o processo químico de tingimento.
\end{abstract}

Palavras-chave: redes neurais; fiação; fibras imaturas; algodão.

\section{Introdução}

Um desequilíbrio nutricional na planta de algodão pode ocasionar abertura dos capulhos (maçã do algodão aberta) tardiamente, ocasionando fibras imaturas. Segundo SEBRAE (2006), isso "ocorre quando existe um excesso de nitrogênio ou uma abertura precoce, ou quando a adubação 
fosfatada é desproporcional". As fibras imaturas também formam neps, que são responsáveis por irregularidades no fio e também tendem a deixar pontos destacados após o tingimento, especialmente quando compostos por fibras imaturas.

Procuramos por meio deste trabalho apresentar o desenvolvimento de uma metodologia para determinar o grau de imaturidade das fibras, com o objetivo de antever os problemas no tingimento de fios formados com um alto teor de fibras imaturas.

Com o uso de características determinadas por equipamento HVI (High Volume Instrument), como maturidade, alongamento e micronaire, se desenvolveu um método de classificação das fibras de algodão quanto ao índice de fibras imaturas (IFI). Esse método consiste na elaboração de gráficos de correlação entre várias variáveis, utilizando redes neurais artificiais para a construção dos mesmos.

Analisando várias amostras de algodão e classificando-as com relação à apresentação de fibras imaturas após o tingimento, foi possível construir duas cartas de correlação com as quais se determina com precisão, o nível de fibras imaturas na amostra. Assim, podemos antever problemas que ocorrerão após o tingimento de uma amostra, sem a necessidade de se realizar o processo químico de tingimento.

\section{Referencial teórico}

\subsection{O processo produtivo das fiações de algodão}

Segundo Ribeiro (1984, p. 28), a tecnologia está voltada ao estudo da produção de fios. Neste contexto a palavra fiação refere-se à conversão de grande quantidade de fibras individuais não ordenadas, de comprimento relativamente curto, em um produto linear, ordenado e de comprimento muito grande, utilizando dispositivos e máquinas apropriadas.

$\mathrm{Na}$ indústria têxtil brasileira a fibra que mais se destaca é o algodão. Segundo ABIT (2014), na safra 2013 seu consumo foi de aproximadamente 53,5\% do total de fibras consumidas e 97,7\% do total de fibras naturais consumidas.

No processo de fiação do algodão a matéria-prima representa em torno de $95 \%$ do custo de produção do fio (LIMA, 2000). Este fato isolado é suficiente para indicar a importância da matériaprima no processo de produção de fio.

\subsubsection{Características das fibras de algodão}

As características físicas das fibras de algodão são ferramentas importantes e seu conhecimento permite decidir quanto à sua forma de consumo, os ajustes das variáveis do processo e uma série de outras providências correlatas. Para tanto, é necessário medir e avaliar os valores das 
principais características das fibras, relacionando-os com o sistema de fiar e com o produto a elaborar.

Sabe-se que:

\begin{abstract}
As principais características da fibra de algodão são: o comprimento, a uniformidade do comprimento, a espessura (micronaire), a maturidade, a resistência, o tipo, a umidade e a quantidade de açúcar presente no algodão, denominada de honeydew ou caramelização, aceitável para o sistema de fiação em uso (LEWIN e PEARCE, 1985).
\end{abstract}

Fatores como a região de produção, a safra, o armazenamento e o transporte influem na existência de diversos tipos de algodão, com características diferenciadas. A escolha de uma fibra deve levar todas essas características em conta, em função do produto que se deseje fabricar.

Existe forte correlação entre as próprias características da fibra e também forte correlação entre a qualidade do fio e as características da fibra (LIMA, 1992).

\title{
2.2. Redes neurais artificiais
}

Redes neurais artificiais é um conceito da computação que visa trabalhar o processamento de dados de maneira semelhante ao cérebro humano. O cérebro é tido como um processador que é altamente complexo e realiza processamentos de maneira paralela. Para isso, ele organiza sua estrutura, ou seja, os neurônios, de forma que eles realizem o processamento necessário. Isso é feito numa velocidade extremamente alta e não existe qualquer computador no mundo capaz de realizar o que o cérebro humano faz.

Nas redes neurais artificiais, a ideia é realizar o processamento de informações tendo como princípio a organização de neurônios do cérebro. Como o cérebro humano é capaz de aprender e tomar decisões baseadas na aprendizagem, as redes neurais artificiais devem fazer o mesmo. Assim, uma rede neural pode ser interpretada como um esquema de processamento capaz de armazenar conhecimento baseado em aprendizagem (experiência) e disponibilizar este conhecimento para a aplicação em questão.

\subsubsection{Funcionamento das redes neurais artificiais}

As redes neurais artificiais são criadas a partir de algoritmos projetados para determinada finalidade. É impossível criar um algoritmo desses sem ter conhecimento de modelos matemáticos que simulem o processo de aprendizado do cérebro humano.

Basicamente, uma rede neural se assemelha ao cérebro em dois pontos: o conhecimento é obtido através de etapas de aprendizagem, e pesos sinápticos são usados para armazenar o conhecimento. Sinapse é o nome dado à conexão existente entre neurônios. Às conexões são 
atribuídos valores, que são chamados de pesos sinápticos. Isso deixa claro que as redes neurais artificiais têm em sua constituição uma série de neurônios artificiais (ou virtuais) que serão conectados entre si, formando uma rede de elementos de processamento.

A representação esquemática de um EP (elemento de processamento, ou neurônio) é apresentada vista na Figura 1. Cada elemento é numerado, de um até i-ésimo elemento, recebendo várias entradas $\left(\mathrm{x}_{\mathrm{j}}\right)$ e possuindo uma única saída $\left(\mathrm{o}_{\mathrm{i}}\right)$. Cada conexão de entrada é associada a um peso ou força da conexão $\left(\mathrm{w}_{\mathrm{ij}}\right)$ (FREEMAM e SKAPURA, 1992).

O valor líquido de entrada do elemento é uma somatória do produto das conexões e seus respectivos pesos. Assim, o valor líquido da entrada do i-ésimo elemento pode ser escrito como:

$$
\alpha_{i}=\sum_{j}^{N} w_{i j} x_{j}
$$

onde, $\mathrm{N}$ representa o total de conexões de entrada do elemento de processamento. Esse valor líquido $\left(\alpha_{\mathrm{i}}\right)$ recebe o nome de valor de ativação, ou simplesmente ativação.

Figura 1 - Estrutura de um elemento de processamento

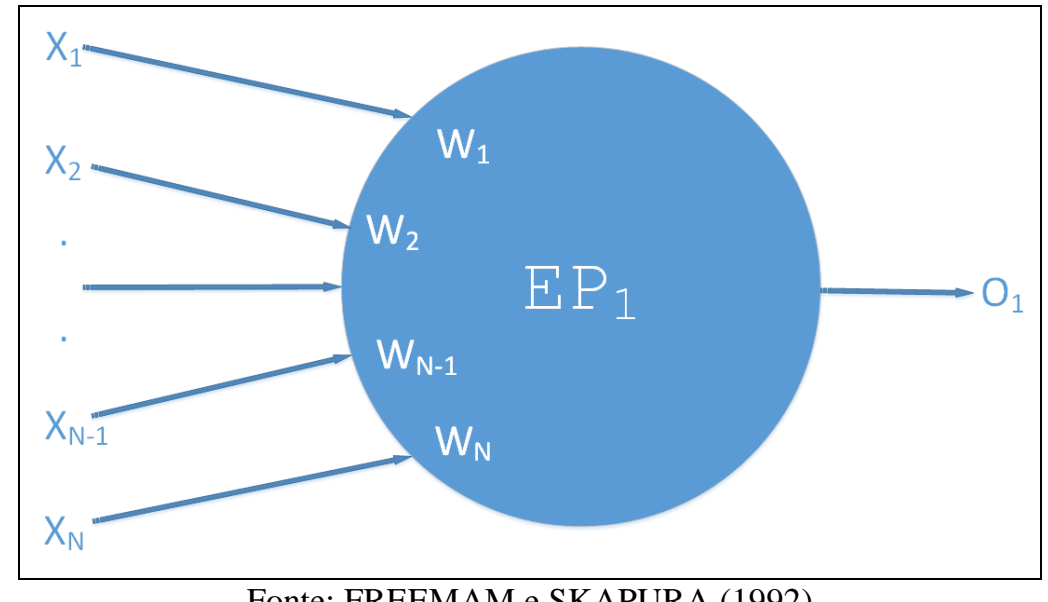

Fonte: FREEMAM e SKAPURA (1992)

A saída do elemento de processamento é determinada a partir da ativação através da aplicação de funções lineares ou não-lineares, as chamadas funções de ativação. Podemos representar a saída dos elementos como:

$$
o_{i}=f_{i}\left(\alpha_{i}\right)
$$

Sendo que, $f_{i}$ representa a função de ativação do $i$-ésimo elemento, e a escolha da função de ativação a usar depende do tipo de problema que esteja sendo resolvido. As funções de ativação mais utilizadas são a linear, a sigmoidal e a hiperbólica.

Analisando-se apenas dois tipos de funções de ativação, a linear e a sigmoidal, verifica-se que no primeiro tipo, o valor da função assume o mesmo valor da ativação:

$$
f_{i}\left(\alpha_{i}\right)=\alpha_{i}
$$


Nesta equação, $i$ representa o $i$-ésimo elemento de processamento e neste caso, a função fornece às redes neurais artificiais características lineares.

No segundo tipo, onde a função apresenta características não-lineares, têm-se;

$$
f_{i}\left(\alpha_{i}\right)=\frac{1}{\left(1+e^{-\alpha_{i}}\right)}
$$

Observa-se que a função sigmoidal é limitada pelos valores extremos 0 e 1 . Essa característica da função sigmoidal atua como um limitante do sinal de saída, fornecendo valores com extremos bem-definidos. É interessante notar que a não-linearidade da função sigmoidal também é observada no comportamento dos neurônios humanos (WILLIS et al, 1990). Atuando sobre uma rede neural, esta função fornece a ela a capacidade de representar relações não-lineares.

Existem várias formas de se desenvolver uma rede neural. Ela deve ser montada de acordo com o(s) problema(s) a ser(em) resolvido(s). Em sua arquitetura são determinados o número de camadas usadas, a quantidade de neurônios em cada camada, o tipo de sinapse utilizado, etc.

Tendo-se uma RNA ${ }^{1}$ montada, uma série de valores pode ser aplicada sobre um neurônio, sendo que este está conectado a outros pela rede. Estes valores (ou entradas) são multiplicados no neurônio pelo valor do peso de sua sinapse. Então, esses valores são somados. Se esta soma ultrapassar um valor-limite estabelecido, um sinal é propagado pela saída (axônio) deste neurônio. Em seguida, essa mesma etapa se realiza com os demais neurônios da rede. Isso quer dizer que os neurônios vão enfrentar algum tipo de ativação, dependendo das entradas e dos pesos sinápticos.

Um esquema representativo é mostrado na Figura 2, onde se visualizam as conexões dos elementos de processamento em três camadas com vários elementos em cada uma.

Figura 2 - Esquema representativo das conexões dos neurônios s de uma RNA

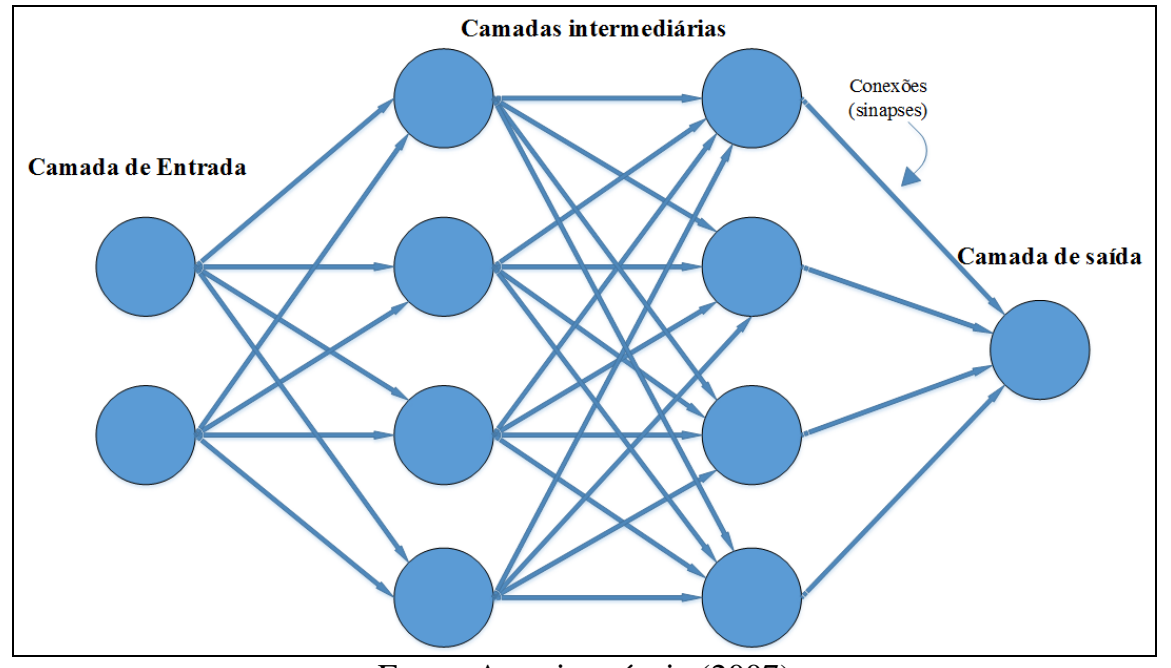

Fonte: Autoria própria (2007)

\subsubsection{Topologia de redes neurais artificiais}

\footnotetext{
${ }^{1}$ RNA - Rede Neural Artificial
} 
A entidade de processamento definida na Figura 1 é relativamente simples, calcula uma função de saída $o_{i}$ a partir das entradas $x_{j}$ e dos pesos $w_{i j}$, com uma função de ativação pré-definida. O potencial e a flexibilidade do cálculo baseado em redes neurais vêm da criação de conjuntos de neurônios que estão interligados entre si. Esse paralelismo de elementos com processamento local cria a "inteligência" global da rede. Um elemento da rede recebe um estímulo nas suas entradas, processa esse sinal e emite um novo sinal de saída que por sua vez é recebido pelos outros elementos.

Uma categorização fundamental da topologia dos neurônios pode ser feita em relação ao método de propagação da informação recebida, conforme mostra a Figura 4. Pode-se fazer distinção entre redes de propagação para frente (feedforward) e redes realimentadas (recurrent). No caso das redes de propagação para frente o fluxo de informação é unidirecional. Neurônios que recebem a informação simultaneamente agrupam-se em camadas. Camadas que não estão ligadas às entradas nem às saídas da rede chamam-se camadas escondidas. Exemplos para esse tipo de rede são o perceptron (ROSENBLATT, 1958), o perceptron multicamada (MultyLayer Perceptron) (RUMELHART et al., 1986) e o ADALINE (WIDROW e HOFF, 1960). Uma rede que adicionalmente tem uma relação topológica de vizinhança entre os neurônios é o mapa autoorganizável de Kohonen (KOHONEN, 1972 e 1990).

Figura 3 : Topologias principais de redes neurais artificiais

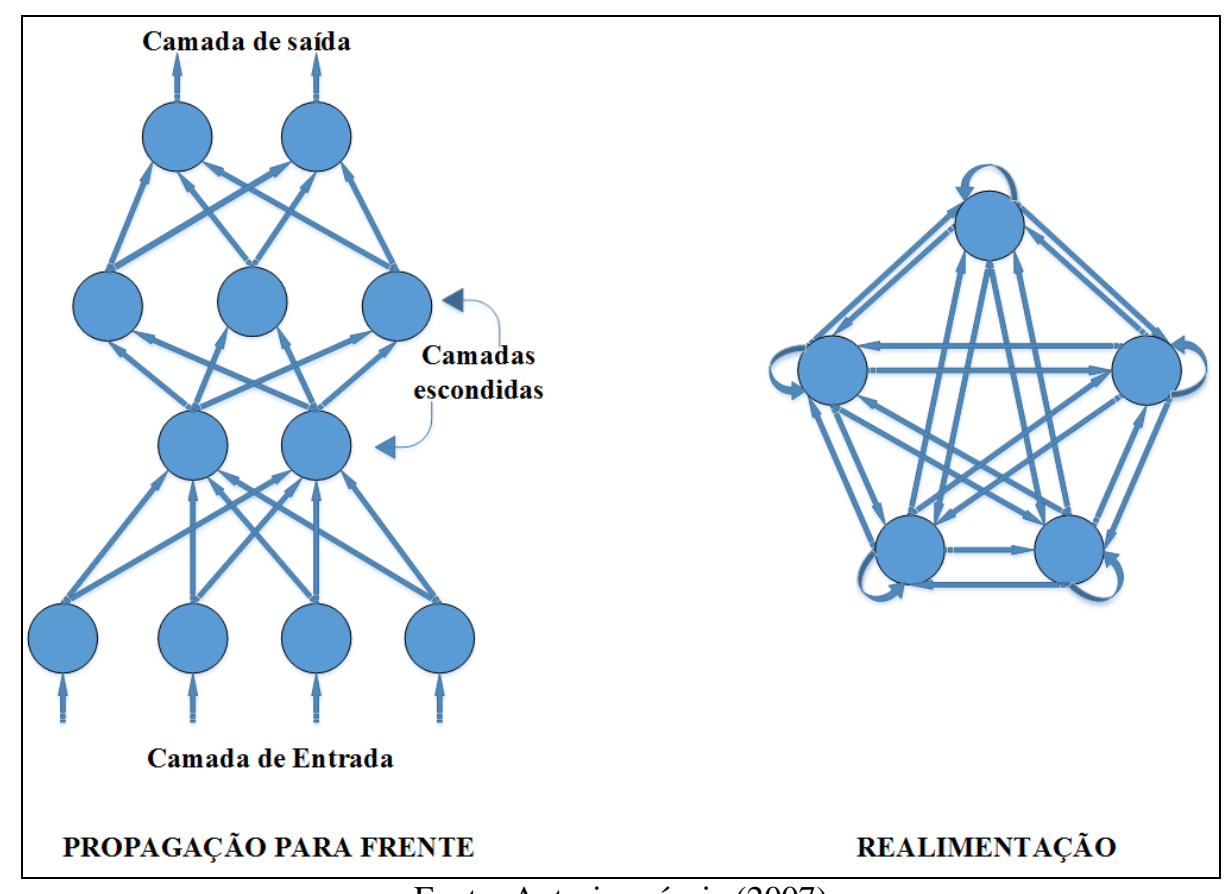

Fonte: Autoria própria (2007)

Redes realimentadas têm ligações entre os neurônios sem restrições. Ao contrário das redes sem realimentação, o comportamento dinâmico desempenha um papel fundamental nesse modelo. Em alguns casos os valores de ativação da rede passam por um processo de relaxação até chegarem 
a um estado estável. O modelo de rede auto-associativa de Hopfield é um exemplo deste tipo de rede (HOPFIELD, 1982).

\subsubsection{0 aprendizado}

O processo de aprendizagem das redes neurais é realizado quando ocorrem várias modificações significantes nas sinapses dos neurônios. Essas mudanças se dão de acordo com a ativação dos neurônios. Se determinadas conexões são mais usadas, estas são reforçadas, enquanto as demais são enfraquecidas. É por isso que quando uma rede neural artificial é implantada para uma determinada aplicação, é necessário um tempo para que esta seja treinada.

O melhor exemplo de algoritmo de treinamento é o Back propagation, desenvolvido independentemente por RUMELHART et al. (1986), WERBOS (1974), e PARKER (1985). Algoritmos modernos de segunda ordem, como Conjugate gradiente descent (BISHOP, $1995 \mathrm{e}$ SHEPHERD, 1997) e Levenberg-Marquardt ${ }^{2}$ (PRESS et al., 1992; BISHOP, 1995 e SHEPHERD, 1997) são substancialmente rápidos para a maioria dos problemas, mas o Back propagation ainda possui vantagens em algumas circunstâncias e é um algoritmo de fácil compreensão.

Segundo STATISTICA (2006) se a rede tiver uma única saída e o problema tiver valores residuais baixos, o treinamento mais indicado é o Levenberg-Marquardt.

As redes lineares, com funções de ativação linear na camada da saída, são otimizadas eficientemente, usando a técnica Pseudo-Inverse (GOLUB e KAHAN, 1965; PRESS et al., 1992 e BISHOP, 1995). Este algoritmo é também conhecido com SVD (Singular Value Decomposition), decomposição de valores singulares.

\section{Treinamento Back propagation}

O algoritmo de treinamento Back propagation é baseado no cálculo do gradiente de uma função erro $(E)$. Como o gradiente informa a direção em que a função é crescente, esse método caminha em direção oposta ao gradiente, ou seja, para um ponto de menor valor da função erro definida. Assim, uma vez atingido o ponto de mínimo da função, têm-se os valores dos pesos que produzem os menores erros de saída (ANTONELLI, 1998).

Durante o processo de treinamento a correção dos pesos é realizada no sentido inverso da rede, ou seja, da saída para a entrada. Diz-se que o erro propaga-se para trás (back propagation).

\section{Treinamento Levenberg-Marquardt}

\footnotetext{
${ }^{2}$ Apresentado por LEVENBERG, 1944 e posteriormente atualizado por MARQUARDT, 1963. Foi totalmente reescrito por PRESS et al., 1992 e ajustado por BISHOP, 1995 e SHEPHERD, 1997
} 
O treinamento Levenberg-Marquardt é um avançado algoritmo de otimização não-linear. Somente pode ser utilizado em estruturas de rede que permitem a propagação para trás do erro.

O algoritmo Levenberg-Marquardt trabalha fazendo a suposição que a função desconhecida do problema, que está sendo modelada pela rede neural é linear. Baseado neste cálculo, o mínimo pode ser determinado exatamente em uma única etapa. O mínimo calculado é testado, e se o erro determinado for menor que ao atual, o algoritmo move os pesos para o novo ponto. Este processo é repetido iterativamente em cada execução. Desde que a suposição linear seja mal fundamentada, pode facilmente conduzir o método a testar um ponto que seja inferior (talvez mesmo absurdamente inferior) ao atual. $\mathrm{O}$ aspecto inteligente de algoritmo Levenberg-Marquardt, é que a determinação do ponto novo é realmente um acordo entre uma etapa no sentido da descida ao ponto de menor erro e o salto acima mencionado. As etapas bem sucedidas são aceitas e conduzem a um fortalecimento da suposição das linearidades (que é aproximadamente verdadeira próxima a um mínimo). As etapas mal sucedidas são rejeitadas e conduzem a uma etapa em decida mais cautelosa. Assim, o algoritmo Levenberg-Marquardt continuamente alterna a sua aproximação e pode fazer o progresso muito rápido (STATISTICA, 2006).

Esse método apresenta convergência em menos iterações, mas requer mais cálculos por iteração devido ao cálculo de matrizes inversas. Apesar do grande esforço computacional, ele continua sendo o algoritmo de treinamento mais rápido para redes neurais quando se trabalha com um número moderado de parâmetros na rede (entradas e a saídas). Se esse número é elevado, a utilização desse algoritmo é pouco prática (STATISTICA, 2006).

Treinamento Pseudo-Inverse (Singular Value Decomposition)

Este algoritmo usa a técnica de decomposição em valores singulares (SVD) para calcular uma matriz pseudo-inversa necessária para ajustar os pesos de uma camada de saída linear (função de ativação linear). Essencialmente, garante encontrar o ajuste ótimo para os pesos em uma camada linear, minimizando o erro ajustado (BISHOP, 1995). Esta é a técnica padrão de otimização dos mínimos quadrados.

As técnicas lineares são extremamente importantes na otimização, porque é possível encontrar uma solução ótima a um modelo linear - algo que não está garantido com modelos nãolineares. O procedimento Pseudo-Inverse além de encontrar o menor erro absoluto, é também, relativamente rápido (STATISTICA, 2006).

\section{Treinamento Conjugate gradient descent}

O algoritmo de treinamento Conjugate gradiente descent é um avançado método de treinamento para redes multilayer perceptron. Possui performance geralmente melhor do que o treinamento Back propagation, e pode ser aplicado em todos os casos que se usa o treinamento 
Back propagation. Esta é uma técnica recomendada para qualquer rede com um número grande de pesos (mais de uma centena) e/ou múltiplas unidades de saídas.

O Conjugate gradiente descent é um algoritmo do grupo de atualização em lote: enquanto o algoritmo Back propagation ajusta os pesos da rede um de cada vez, o algoritmo Conjugate gradiente descent trabalha com a saída média do gradiente da superfície do erro sobre todos os casos, e atualiza todos os pesos de uma vez no fim da iteração. Por esta razão, não há necessidade de selecionar parâmetros como passos de aprendizagem ou razão de momento para o algoritmo, assim, a sua utilização se torna mais fácil em relação ao treinamento Back propagation (STATISTICA, 2006).

\subsection{O software $\mathrm{SNN}$}

O software SNN (STATISTICA: NEURAL NETWORKS ${ }^{\circledR}$ ) oferece grande flexibilidade para definição de arquiteturas e treinamento de redes.

Com o recurso IPS (Inteligent Problem Solve), existente no SNN, se define as estruturas de redes a serem treinadas. O IPS é uma ferramenta sofisticada que ajuda a criar e testar redes neurais para problemas de análise e predição de dados. Projeta um número de redes para resolver o problema e seleciona aquelas com melhores resultados, baseando-se em análises de desempenho da rede.

O SNN divide o conjunto de dados em três subconjuntos: os casos para treinamento, os casos para seleção e os casos para teste. Essa divisão é feita de forma randômica, na proporçãopadrão de 2:1:1, ou seja, para cada dois casos de treinamento temos um caso para a seleção e um caso para o teste. Entretanto, o usuário pode alterar essa proporção como lhe convier.

No SNN as redes neurais são treinadas usando-se somente o subconjunto de treinamento. O subconjunto de seleção é usado para manter uma checagem independente sobre o desempenho da rede durante o treinamento, porque um aumento excessivo do erro no subconjunto de seleção indica um over-learning. Durante a execução do IPS, se um over-learning ocorre, o treinamento é encerrado e o estado da rede é restabelecido para o de menor valor do erro no subconjunto de seleção.

A performance de uma rede, no sistema SNN, é realizada por meio de índices obtidos com os subconjuntos de treinamento, de seleção e de teste. Esses índices são determinados pela relação entre os desvios-padrão do residual e os desvios-padrão dos dados observados de saída. Se somente os dados observados da saída estivessem disponíveis, sem nenhuma variável de entrada, a melhor estimativa que poderíamos fazer da variável de saída, para um novo caso, seria o valor médio dos valores observados de saída no subconjunto do treinamento. Se isso fosse feito, os residuais seriam os valores observados menos a média, e o erro médio seria, consequentemente, o desvio-padrão da 
variável de saída. Quando se usa uma rede neural, espera-se, obviamente, que os residuais sejam menores do que o erro médio. A relação relatada mede esta melhoria. Uma relação de 1.0 implica que a rede está fazendo nada melhor do que a mais ingênua estimativa disponível, e consequentemente que, ou não há nenhuma informação útil nas variáveis da entrada, ou a rede não está usando a informação com sucesso. À medida que o desempenho da rede melhora, a relação torna-se mais perto de zero.

Outro fator disponível para análise de desempenho, é o valor da função erro determinada para cada subconjunto analisado. A função erro geralmente utilizada é a erro-quadrático, que soma as diferenças quadradas entre os valores previstos e os observados na saída da rede.

\section{Aplicação de redes neurais artificiais na indústria de fios Cocamar®}

A quantidade de fibras imaturas também é uma característica importante da matéria-prima, porque afeta diretamente a qualidade do processo de tingimento do fio. Um desequilíbrio nutricional na planta de algodão pode ocasionar abertura dos capulhos (maçã do algodão aberta) tardiamente, propiciando a formação de fibras imaturas. Isto ocorre quando existe um excesso de nitrogênio ou uma abertura precoce, ou quando a adubação fosfatada é desproporcional. As fibras imaturas também formam neps, que são responsáveis por irregularidades no fio e também tendem a deixar pontos destacados após o tingimento, especialmente quando compostos por fibras imaturas.

Sabendo-se da necessidade dessa informação, aplicaram-se RNAs na determinação do índice de fibras imaturas, e para essa aplicação fez-se uso do software SNN.

O índice de fibras imaturas é influenciado diretamente pelas condições de formação da planta, sendo possível determiná-lo por meio de outras características da fibra, como comprimento, alongamento, maturidade, resistência, micronaire (espessura) e SFI (Índice de Fibras Curtas).

O Laboratório de Controle de Qualidade, da fiação da empresa Cocamar ${ }^{\circledR}$, determinou qualitativamente a quantidade de fibras imaturas em 56 amostras de algodão por meio de análises químicas (tingimento) com o auxílio de procedimentos padronizados pela empresa. Nessas análises, utilizou-se o processo de tricomia de cores, sendo possível a identificação de fibras imaturas na amostra de algodão pela absorção da cor verde e fibras maturas pela absorção da cor vermelha. Entretanto, é necessário utilizar corantes especiais, com alto teor de pureza, para que os resultados não sejam mascarados. Utilizou-se o corante verde Solophenyl BL e o corante vermelho Difenil 5 BL. Cada ensaio de determinação do índice de fibras imaturas realizado no laboratório levou, em média, uma hora para ser concluído, uma vez que se têm as fases de preparação da amostra, tingimento, secagem e classificação. A classificação do índice de fibras imaturas é realizada de modo subjetivo, através do aspecto visual final da amostra, devendo-se observar a distribuição relativa dos corantes vermelho e verde sobre a mesma. Essa distribuição pode variar de um 
vermelho pronunciado (alto grau de fibras maturas) a um verde distinto (alto grau de fibras imaturas). Para a classificação das amostras, padronizou-se índice de fibras imaturas de acordo com a Tabela 1, que define uma grandeza mensurável e de fácil interpretação.

Tabela 1 - Classificação do IFI (Índice de Fibras Imaturas)

\begin{tabular}{ccc}
\hline IFI & Descrição & Classificação quanto à distribuição da cor \\
\hline 1 & Baixa incidência de fibras imaturas & Vermelho pronunciado \\
2 & Média incidência de fibras imaturas & Vermelho fraco \\
3 & Média forte incidência de fibras imaturas & Verde fraco \\
4 & Forte incidência de fibras imaturas & Verde pronunciado \\
\hline
\end{tabular}

Fonte: Cocamar (2002)

Para a determinação do IFI (Índice de Fibras Imaturas) por meio do uso de redes neurais artificiais, utilizou-se o recurso IPS para determinar a estrutura da RNA. O conjunto de dados foi dividido nos três subconjuntos - treinamento, seleção e teste - na proporção 2:1:1 respectivamente. O SNN permite a divisão do treinamento em duas fases, podendo-se, em cada fase, escolher o tipo de treinamento, seus parâmetros e o número de iterações. $O$ treinamento da rede para determinar o índice de fibras imaturas foi dividido em duas fases: um treinamento inicial utilizando um algoritmo Back propagation (com 100 iterações, passo de aprendizagem $\eta=0.01$ e coeficiente de momento $\beta=0.3$ ) e um segundo treinamento utilizando um algoritmo Levenberg-Marquardt com 200 iterações.

Na Tabela 2 têm-se as características das fibras, com as respectivas faixas de valores, utilizadas como variáveis de entrada da rede neural.

Tabela 2 - Características das fibras utilizadas para determinar o índice de fibras imaturas

\begin{tabular}{cccccc}
\hline Característica & \multicolumn{5}{c}{ Valores Estatísticos } \\
& Min. & Máx. & Méd. & D. Pad. & C. V. $(\%)$ \\
\hline Micronaire $\left(\mu \mathrm{g} / \mathrm{in}^{2}\right)$ & 3,10 & 4,50 & 3,90 & 0,40 & 10,60 \\
Maturidade & 0,83 & 0,94 & 0,89 & 0,04 & 4,00 \\
Comprimento $(\mathrm{mm})$ & 27,90 & 30,43 & 29,02 & 0,66 & 2,26 \\
Uniformidade $(\%)$ & 77,70 & 88,00 & 81,50 & 1,50 & 1,90 \\
SFI $(\%)$ & 6,70 & 11,30 & 9,10 & 1,00 & 10,90 \\
Resistência $(\mathrm{gf} / \mathrm{tex})$ & 27,50 & 33,80 & 33,30 & 1,30 & 4,20 \\
Alongamento $(\%)$ & 7,00 & 9,20 & 8,10 & 0,50 & 6,40 \\
Umidade $(\%)$ & 5,50 & 8,50 & 7,82 & 0,66 & 8,45
\end{tabular}

Legenda: Min.=Valor mínimo, Max.=Valor máximo, Méd.=Valor médio, D.Pad =Desvio padrão e C.V.=Coeficiente de variação

Fonte: Cocamar (2002)

O IPS do SNN, por meio da pesquisa em um conjunto de 200 (duzentas) redes diferentes com os mais variados tipos de estrutura, selecionou três variáveis (micronaire, alongamento e 
maturidade) e cinco tipos de estruturas com melhores desempenhos. Os resultados obtidos pelo IPS, durante o processo de definição da estrutura da rede, estão apresentados na Tabela 3.

Na primeira coluna da Tabela 3 tem-se o perfil da rede. Essa coluna mostra, de forma resumida, o tipo da rede, o número de variáveis na entrada e o número de variáveis na saída, o número de camadas e o número de neurônios em cada camada. Essas informações estão apresentadas no formato <tipo><variáveis de entrada $>$ :<camada $1>-<$ camada $2>-<$ camada 3>:<variáveis de saída>, onde o número de camadas pode variar. Por exemplo, o perfil MLP 7:711-9-1:1 significa uma rede do tipo MultiLayer Perceptron com sete variáveis de entrada e uma variável de saída, e quatro camadas de 7,11, 9 e 1 neurônio respectivamente.

Observa-se que a rede de perfil Linear 3:3-1:1 apresentou o melhor índice de performance no conjunto de seleção e menor valor da função erro no conjunto de treino.

Tabela 3 - Resultados da seleção RNA para determinar o índice de fibras imaturas

\begin{tabular}{ccccccc}
\hline \multirow{2}{*}{ Perfil da Rede } & $\begin{array}{c}\text { Performance do } \\
\text { Treino }\end{array}$ & $\begin{array}{c}\text { Performance da } \\
\text { Seleção }\end{array}$ & $\begin{array}{c}\text { Performance do } \\
\text { Teste }\end{array}$ & $\begin{array}{c}\text { Erro } \\
\text { Treino }\end{array}$ & $\begin{array}{r}\text { Erro } \\
\text { Seleção }\end{array}$ & $\begin{array}{c}\text { Erro } \\
\text { Teste }\end{array}$ \\
\hline RBF 3:3-3-1:1 & 0,2125 & 0,6678 & 0,5757 & 0,1874 & 0,7410 & 0,6115 \\
GRNN 3:3-8-2-1:1 & 0,1260 & 0,6523 & 0,5385 & 0,1111 & 0,7232 & 0,5216 \\
Linear 3:3-1:1 & 0,2123 & 0,3196 & 0,3903 & 0,0702 & 0,2996 & 0,2234 \\
MLP 3:3-11-1:1 & 0,2943 & 0,5053 & 1,0877 & 0,1256 & 0,5109 & 0,5152 \\
MLP 3:3-11-11-1:1 & 0,2932 & 0,4016 & 0,3151 & 0,0777 & 0,1351 & 0,1850 \\
\hline
\end{tabular}

Legenda: GRNN-Generalized Regression Neural Networks, RBF-Radial Basis Function, MLP-Multilayer Perceptrons e Linear-Linear Network Fonte: Autoria própria (2007)

Devido ao fato de ter-se conseguido uma estrutura de rede simples e um conjunto pequeno de variáveis de entrada explorou-se durante o treinamento outras possibilidades da alimentação da rede. Concluiu-se que a estrutura de rede escolhida produz melhores resultados quando alimentada com o micronaire, a razão e o produto do alongamento e maturidade. Na Figura 5 têm-se a definição da estrutura utilizada e as variáveis de alimentação da rede neural, alteradas conforme descrito anteriormente. 
Figura 5 - Estrutura da RNA utilizada para determinar o índice de fibras imaturas

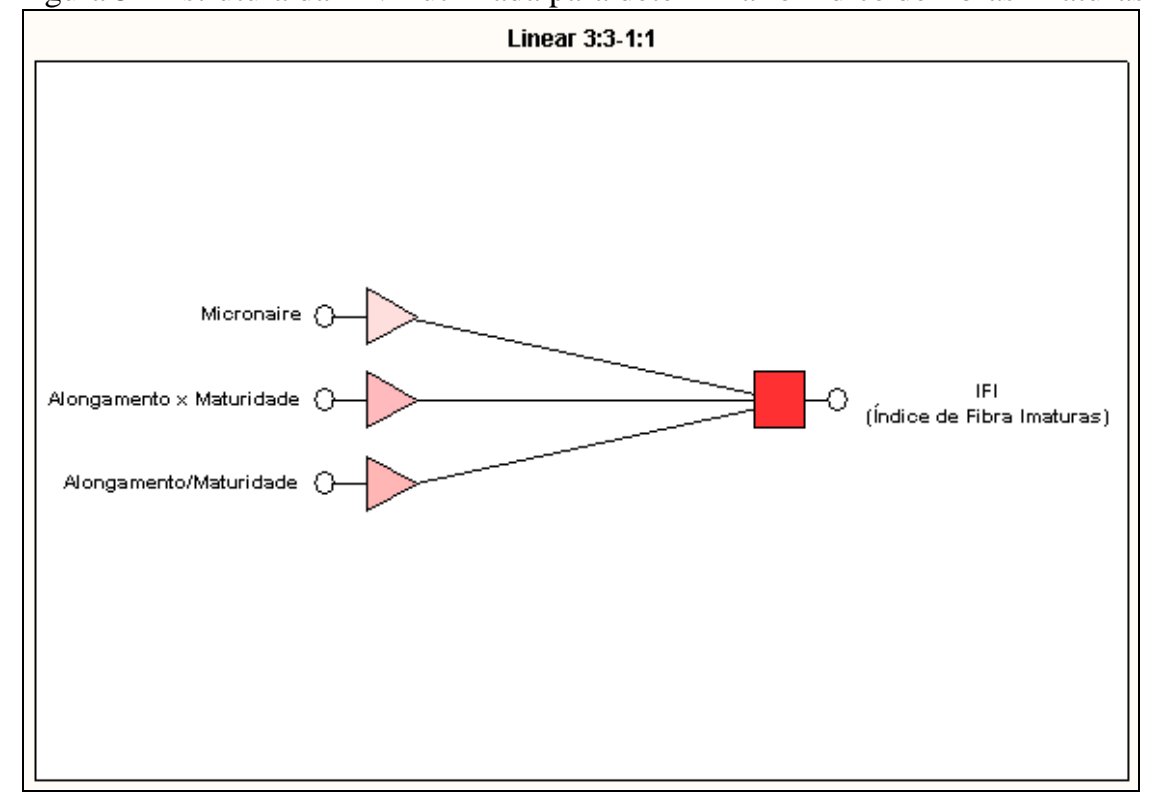

Fonte: Autoria própria (2007)

Com a estrutura apresentada na Figura 5, utilizou-se o treinamento Pseudo-Inverse (Singular Value Decomposition) e funções lineares de ativação nas camadas de entrada e de saída. Com essa rede obteve-se um coeficiente de correlação (R2) de 0,857804 entre os valores observados em laboratório e os valores previstos pela rede. Na Figura 6 tem-se a representação gráfica de desempenho da rede durante o treinamento.

Conforme descrito anteriormente, os valores observados do índice de fibras imaturas são determinados de forma subjetiva, através do aspecto visual final da amostra. Portanto, têm-se na Figura 6 os valores observados na forma de um degrau (linha horizontal descontínua). Os pontos, que representam os valores determinados pela rede, estão distribuídos de forma mais contínua e linear. Observando esse fato, optou-se por redefinir a classificação do índice de fibras imaturas, apresentada na Tabela 4, de modo a representar uma faixa de valores de índices, e não um único valor, tornando-o contínuo. A Tabela 4 representa a redistribuição do índice de fibras imaturas de modo contínuo. 
Figura 6 - Performance da RNA durante o treinamento para determinar o índice de fibras imaturas

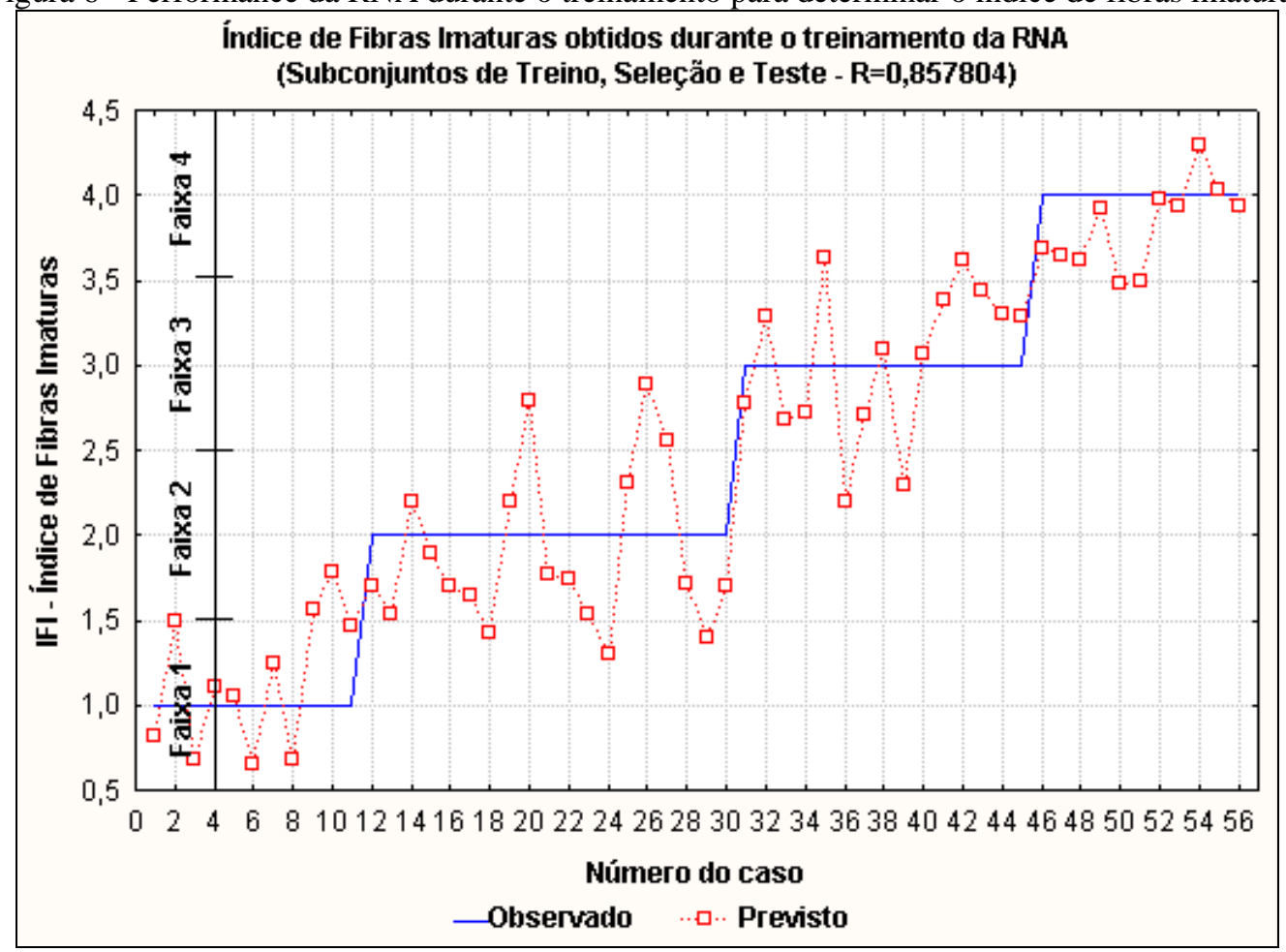

Fonte: Autoria própria (2007)

A redistribuição do índice de fibras imaturas de modo contínuo melhorou o desempenho da RNA na determinação do índice de fibras imaturas. Por exemplo: uma amostra com o valor do $\mathrm{IFI}_{\text {observado }}=1,0$ e o valor do $\mathrm{IFI}_{\text {previsto }}=1,49$ possui um erro absoluto no valor de $49 \%$, entretanto, ambos são classificados na Faixa 1. Por meio dessa nova classificação conseguiu-se que em $84 \%$ dos casos fosse determinada, com exatidão, a faixa do índice de fibras imaturas pela RNA.

Tabela 4 - Classificação contínua dos valores do índice de fibras imaturas

\begin{tabular}{cccc}
\hline \multicolumn{1}{c}{ Descrição } & $\begin{array}{c}\text { Classificação quanto à } \\
\text { distribuição de cores }\end{array}$ & Faixa & Valor \\
\hline Baixa incidência de fibras imaturas & Vermelho pronunciado & 1 & 0,50 a 1,49 \\
Média incidência de fibras imaturas & Vermelho fraco & 2 & 1,50 a 2,49 \\
Média forte incidência de fibras imaturas & Verde fraco & 3 & 2,50 a 3,49 \\
Forte incidência de fibras imaturas & Verde pronunciado & 4 & 3,50 a 4,50 \\
\hline Fonte: Autoria própria (2007)
\end{tabular}

Fonte: Autoria própria (2007) 
Devido à simplicidade da estrutura da RNA obtida e à facilidade de programação do seu algoritmo, foram construídas duas ferramentas gráficas, a Figura 7 e a Figura 8, que disponibilizam de modo prático o conhecimento adquirido pela RNA.

As Figuras 7 e 8, em conjunto, podem determinar o índice de fibras imaturas de uma amostra sem a necessidade de se fazer análise química (tingimento). A Figura 7 foi denominada de Carta ASM (Análise Simplificada da Maturidade) e fornece o valor do IFI de uma amostra classificando-a de acordo com a Tabela 4. No entanto, para se utilizar a Carta ASM é necessário primeiramente entender o Diagrama MRA (Maturidade, Razão e Alongamento) da Figura 8. Nele os valores das características maturidade e alongamento foram disponibilizados de modo a fornecer uma razão (Fator R) entre as duas características. Essa razão não possui nenhum significado físico nem unidades, sendo apenas um referencial para ser utilizado na Carta ASM. Com o valor desse fator e a característica micronaire da amostra é possível determinar a faixa e o índice de fibras imaturas na Carta ASM.

Figura 7 - Carta de Análise Simplificada da Maturidade

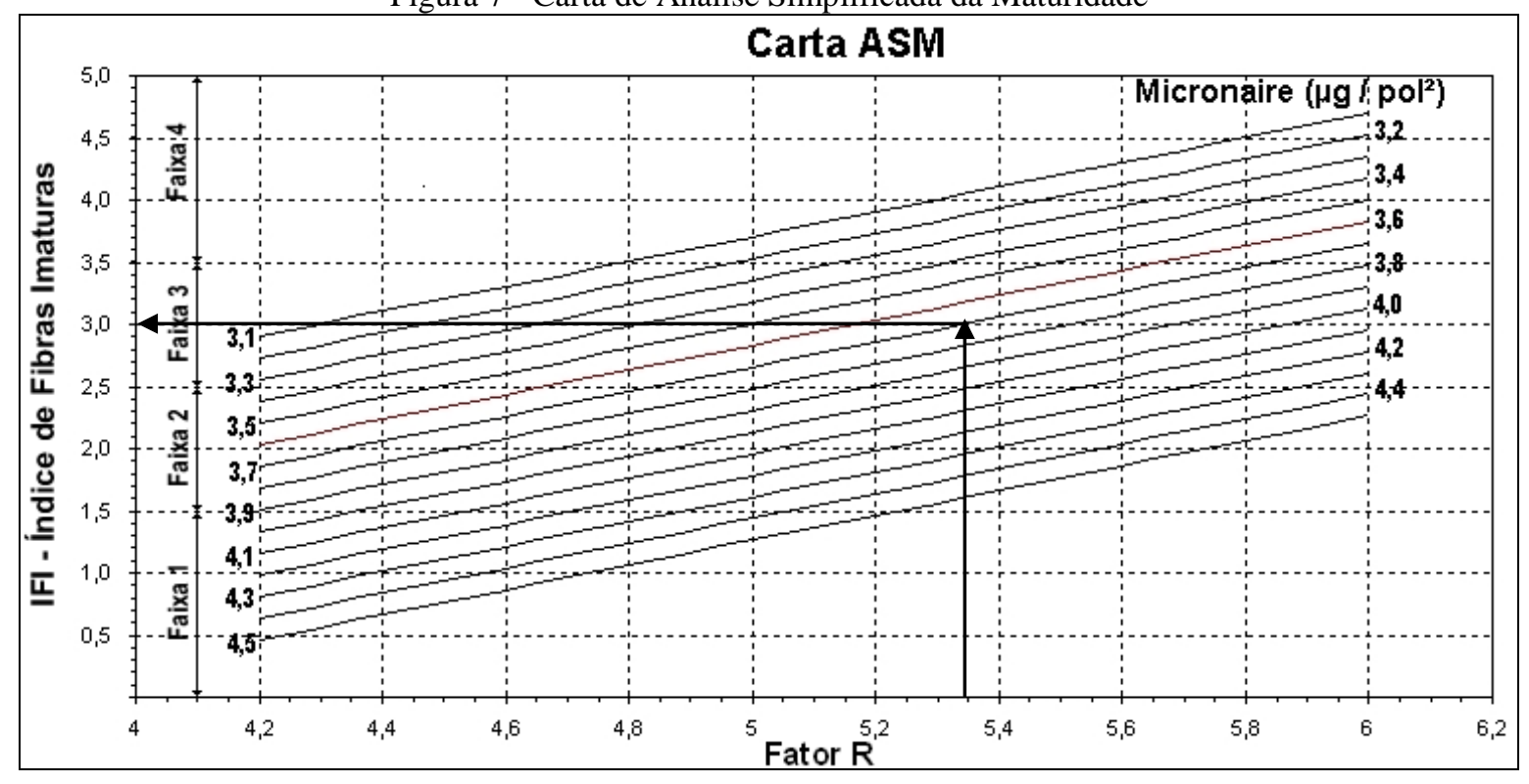

Fonte: Autoria própria (2007)

Figura 8 - Diagrama Maturidade, Razão e Alongamento 


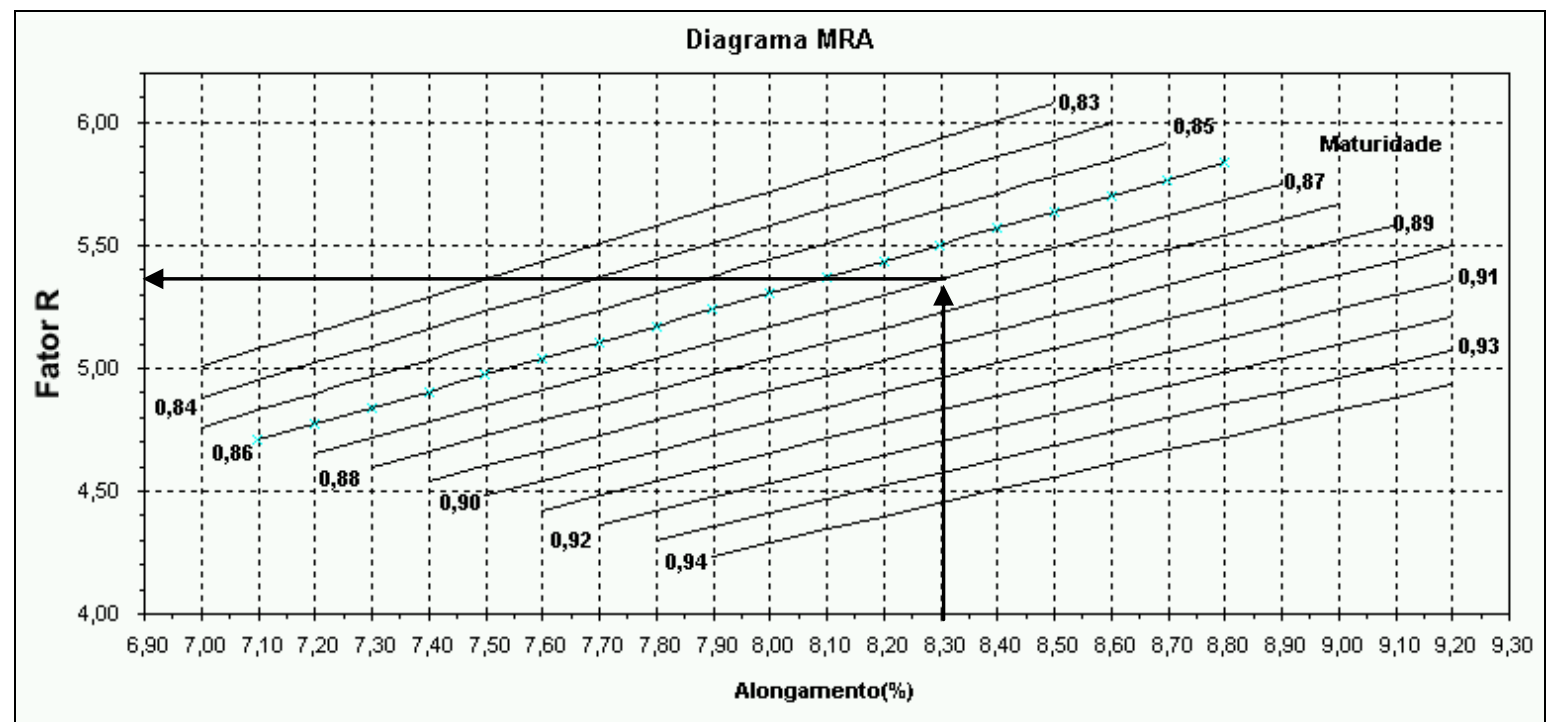

Fonte: Autoria própria (2007)

As setas existentes nas Figuras 7 e 8 representam um exemplo de leitura do valor do índice de fibras imaturas. Neste exemplo, utiliza-se o valor do alongamento da fibra igual a $8.30 \%$, a maturidade igual a 0.87 e a Figura 8, para determinar o valor de 5.38 para o fator R. Com o valor do fator R obtido e o micronaire igual a $3,7 \mu \mathrm{g} / \mathrm{cm}^{2}$ utiliza-se a Figura 7 para determinar o valor de 3.0 para o índice de fibras imaturas, que está distribuído dentro da faixa 3, ou seja, a faixa de média forte incidência de fibras imaturas.

\section{Conclusões e observações}

Os resultados obtidos na aplicação de redes neurais artificiais para determinar o índice de fibras imaturas foram satisfatórios, pois se conseguiu demonstrar que as redes neurais artificiais são capazes de estabelecer uma relação entre as características da fibra de algodão e a quantidade presente de fibras imaturas em uma amostra.

Podem-se antever, para uma amostra de algodão, os problemas que ocorrerão após o tingimento de um fio produzido com a metodologia definida, sem a necessidade de se realizar o processo químico de tingimento. Isso representa um ganho de qualidade na produção do fio, porque se tem a informação do problema antecipadamente e pode-se recomendar ao cliente da indústria de fios o melhor tipo de tingimento a ser realizado com o fio.

Com a utilização dessa metodologia de determinação de fibras imaturas, altera-se o processo, de químico para analítico e consegue-se reduzir o custo das análises. Diminui-se o tempo gasto para a determinação do índice de fibras imaturas, e deste modo, pode-se aumentar a quantidade de amostras a ser analisada. 
A indústria de fios Cocamar®, atualmente possui uma dificuldade em realizar o processo químico de determinação do índice de fibras imaturas, devido à escassez dos corantes utilizados. Essa dificuldade, no futuro, pode ser a força propulsora para a utilização do método apresentado neste trabalho.

\begin{abstract}
In a cotton yarn industry, the quantity of immature fibers is an important feature of the raw material, because it directly affects the quality of the produced yarn dyeing process. A nutritional imbalance in the cotton plant can cause opening of bolls (apple open cotton) late, causing immature fibers, this occurs when there is an excess of nitrogen or an early opening, or when the phosphorus fertilizer is disproportionate. The immature fibers also form neps, which are responsible for irregularities in the yarn and also tend to leave salient points after dyeing, especially when composed of immature fibers. In order to predict problems in the dyeing of yarn formed with a high content of immature fibers, developed a method of classifying cotton fibers using the characteristics (maturity, stretching and micronaire) determined by HVI equipment. This method is the development of correlation graphs between variables, using artificial neural networks to build them. Analyzing multiple samples of cotton and classifying them with respect to the presentation of immature fibers after dyeing, it was possible to construct two correlation with the letters which accurately determines the level of immature fibers in the sample. Thus, the PCP sector (Production Planning and Control) can predict problems that occur after manufacture and dyeing a yarn samples using the raw material without the need for chemical dyeing process.
\end{abstract}

Keywords: neural networks; wiring; immature fibers; cotton.

\title{
Referências
}

ABIT - ASSOCIAÇÃO BRASILEIRA DA INDÚSTRIA TÊXTIL E DE CONFECÇÃO. Apresentada dados de produção e consumo de algodão. Disponível em: 〈http://www.abit.org.br/Servicos.aspx\#36|SD|C〉. Acessado em: 18 de fevereiro de 2014.

ANTONELli, G. C. Controle de Processos com Redes Neurais Inversas. 1998. 110p. Dissertação (Mestrado em Engenharia Química) - Programa de Pós-Graduação em Engenharia Química. Universidade Estadual de Maringá. Maringá.

BISHOP, C. Neural Networks for Pattern Recognition. Oxford: University Press, 1995.

COCAMAR Indústria de Fios. Conhecendo a Empresa - Manual de Integração. Departamento Administrativo, ed. 2002 rev. maio/2002, 2002, 12p.

FREEMAN, J. A.; D. M. SKAPURA. Neural Networks: Algorithms, Applications and Programming Tecniques. Addison-Wesley Publishing Company, 1992.

GOLUB, G. e KAHAN, W. Calculating the singular values and pseudo-inverse of a matrix. SIAM Numerical Analysis, v. 2, n. 2, p. 205-224. 1965.

HOPFIELD, J. J. Neural networks and physical systems with emergent collective computational abilities. Proceeding. The National Academy of Sciences, USA, v. 79, p. 2554-2558, 1982.

KOHONEN, T. Correlation Matrix Memories. IEEE C-21 (4), p. 353-359, 1972.

-----. The self-organizing map. Proceeding. IEEE, v. 78, n. 9, 1990.

LEWIN, M.; PEARCE, E. M. Handbook of Fiber Science and Technology. Volume IV: Fiber Chemistry. New York: Marcel Dekker, 1985.

LIMA, J. J. Controle do Processo de Fiação. Rio de Janeiro: CETIQT/ SENAI, 1992. 
LIMA, F. M. P. de. Análise Econômica entre Tecnologias Diferentes na Indústria Têxtil de Fiação. In: CONGRESSO NACIONAL DE TÉCNICOS TÊXTEIS, XIX, 2000, Fortaleza, Anais... Fortaleza: CNTT, 2000.

PARKER, D.B. Learning logic. Technical Report TR-47, Cambridge, MA: MIT Center for Research in Computational Economics and Management Science. p. 32.1985.

PRESS, W. H.; FLANNERY, B. P.; TEUKOLSKY, S. A. et al. Numerical recipies. 2 ed. New York: Cambridge University Press. 321p. 1992.

RIBEIRO, L. Introdução a Tecnologia Têxtil. v.1. Rio de Janeiro: CETIQT/ SENAI, 1984.

ROSENBLATT, F., The perceptron: A probabilistic model for information storage and organization in the Brain. Psychological Review, v. 65, p. 386-408, 1958.

RUMELHART, D. E.; HINTON, G. E. e WILLIAMS, R. J. Learning internal representations by error propagation. In: Parallel Distributed Processing: Explorations in the Microstructure of Cognition I, Rumelhart, D. E., and McClelland, J. L. (eds.), p. 318-362, MIT Press, Cambridge MA, 1986.

SEBRAE - SERVIÇO BRASILEIRO DE APOIO À MICRO E PEQUENAS EMPRESAS. Sebrae Minas Gerais MG. Ponto de Partida - Para início de negócio - ASSUNTO: CULTIVO DE ALGODÃO. Disponível em: < http://www.dce.sebrae.com.br/bte/bte.nsf/3798620663E0AC5D03256FF0004EB880/\$File/NT000A6D96.pdf >. Acesso em: 29 mai. 2006.

SHEPHERD, A. J. Second-Order Methods for Neural Networks. New York: Springer. 345 p. 1997. STATISTICA SOFTWARE - Data Mining, Statical Analysis, Quality Control. Manual eletrônico do software STATISTICA Neural Networks. Disponível em: 〈http://www.statsoft.com/textbook/stathome.html〉. Acesso em: 25 de outubro de 2006.

WERBOS, P.J. Beyond regression: new tools for prediction and analysis in the behavioural sciences. Tese Ph.D., Harvard University, Boston, MA. 1974.

WIDROW, B. e HOFF, M. E. Adaptive switching circuits. In: 1960 WESCON Convention Record, New York, 1960.

WILLIS, M. J.; C. D. Di MASSIMO; G. A. MONTAGUE; M. T. THAN; A. J. MORRIS: Artificial Neural Networks in Process Engineering, IEE Proceeding-D v.138, n.3, p.256-266, 1990. 


\section{Dados dos autores}

Nome completo: Gilberto Clóvis Antonelli

Filiação institucional: Universidade Estadual de Maringá (UEM)

Departamento: Departamento de Engenharia de Produção

Função ou cargo ocupado: Professor Adjunto

Endereço completo para correspondência: Av. Colombo, 5.790, Jd. Universitário. Maringá - Paraná

- Brasil • CEP 87020-900

Fone: (+5544) 3011-5840 ou (+5544) 3011-4196

e-mail: gcantonelli@uem.br

Nome completo: Ivo Neitzel

Filiação institucional: Faculdade de Telêmaco Borba

Departamento: Departamento de Engenharia Química

Função ou cargo ocupado: Professor

Endereço completo para correspondência: Av. Marechal Floriano Peixoto, 1181 • Alto das Oliveiras

- Telêmaco Borba - Paraná - Brasil • CEP 84266-010.

Fone: +55 42 3271-8000 - Ramal 147

e-mail:ivo.neitzel@fatebtb.edu.br

Submetido: 2014-12-09

Aceito em: 2015-05-07 